Association for Information Systems AIS Electronic Library (AISeL)

ICIS 1984 Proceedings

International Conference on Information Systems

1984

\title{
An Investigation of User-Led System Design: Rational and Political Perspectives
}

Charles R. Franz

University of South Carolina

Daniel Robey

Florida International University

Follow this and additional works at: http://aisel.aisnet.org/icis1984

\section{Recommended Citation}

Franz, Charles R. and Robey, Daniel, "An Investigation of User-Led System Design: Rational and Political Perspectives" (1984). ICIS 1984 Proceedings. 20.

http://aisel.aisnet.org/icis1984/20

This material is brought to you by the International Conference on Information Systems (ICIS) at AIS Electronic Library (AISeL). It has been accepted for inclusion in ICIS 1984 Proceedings by an authorized administrator of AIS Electronic Library (AISeL). For more information, please contact elibrary@aisnet.org. 


\title{
An Investigation of User-Led System Design: Rational and Political Perspectives
}

\author{
Charles R. Franz \\ Management Science Department \\ University of South Carolina
}

\author{
Daniel Robey \\ Department of Management \\ Florida International University
}

\begin{abstract}

\section{INTRODUCTION}

For some time the information systems profession has been interested in behavioral and organizational factors affecting system implementation (Ives and Olson, in press; Robey and Farrow, 1982; Fuerst and Cheney, 1982; Lucas, 1976). However, little research has captured the dynamics of user involvement during system development. Consequently, we know little about such activities and events as user and designer interaction, top management pressures, political activities, or the role of personnel turnover. To learn more about these dynamics, longitudinal research needs to be conducted throughout the system development process.
\end{abstract}

Longitudinal data collection serves two important research objectives: improved measurement validity, and alternative interpretations of events. Events may be described in a more valid manner when data is collected as events occur. This guarantees greater independence of the construct "user involvement" from the construct "system success." In reconstruction studies, respondents' current experience with a system may influence their perceptions of involvement.

Second, longitudinal study makes it easier to collect altemative interpretations of events in the development process. Activities that are ostensibly undertaken for rational reasons (to deliver a better system) may also serve the political interests of the actors (Robey and Markus, 1984). Longitudinal methods permit respondents' interpretations of these events to be collected as they occur.

Through longitudinal research methods, the events of development processes may be described and then interpreted in two ways. One interpretation stresses the rational objectives and methods in development. The second interpretation of the same events identifies political themes. These two perspectives coexist and complement one another.

\section{A DUAL PERSPECTIVE}

The formal purpose of rational project management is to reduce the risks of systems projects, such as failure to obtain anticipated benefits, excessive time and cost for implementation, and poor technical performance (Cash, McFarlan, and McKenney, 1983 , p. 313). The tools prescribed for avoiding such consequences include user involvement, steering committees, formal approval of specifications, progress reports, frequent meetings, etc.

* This paper is forthcoming in Communication of the ACM. 
Organization analysts have recently urged researchers to look beyond such rational assumptions (Burrell and Morgan, 1979). Organizations may also be viewed as arenas for political activity where actors engage in conflict and negotiate for their private interests (Mintzberg, 1983). Kling (1980) suggests that political analysis is appropriate where a plurality of actors disagree on goals and priorities. Since politically-motivated actions may carry consequences for system outcomes, users may resist or sabotage systems that do not fulfill their needs, and support design features which enhance their own situations.

\section{RESEARCH METHOD}

In the current study, data were collected over a two year period from twenty-two members of a medium-sized insurance company. Intensive data were collected for the study by using a variety of measurements over a two year period of time. Data gathering methods consisted of questionnaires, critical incident files, unstructured interviews, documents and memoranda, observation at meetings, and tape recordings.

In gathering data, we deliberately attempted to accomplish two objectives. First, evidence from various sources was compiled to produce a process description. Second, a variety of subjective interpretations from the actors about these events were obtained from the data. From these we were able to detect two predominant themes about the events in the process. These dual interpretations, however, reflect the meaning provided by the actors rather than the researchers' preconceived notions. Importantly, actors' impressions were secured as the events unfolded rather than after the system was developed

The system development process in the case system is viewed as three phases: 1) enhancements to the old system, 2) development of user functional specifications for AUTO, and 3) design of program modules, system logic, and database, The paper analyzes each phase in turn, describing the rational and political themes during each phase in turn, describing the rational and political themes during each phase of the development process. In phase I-enhancement to old system-the rational theme was choice of system design approach, while the political theme was control of system development. During phase I-development of user functional specificationsvalidity of design specifications was the rational theme, while the political theme was maintaining basis of power. In phase III-design of program modules, system logic, and database-project management was the rational theme, while escaping blame was the political theme.

\section{CONCLUSION}

The dual perspective analysis shows that system development can be viewed as both a rational and political process. The rational explanation suggests that events facilitate the timely delivery of a high quality system. The political view stresses the actors' private interests and strategies for controlling the design process while avoiding blame for any problems. Our conclusion examines how these two perspectives are related to each other and provides some general thoughts on managing system development.

Boland and Pondy (1983) argue that rational and "natural" myths coexist in organizations and that significant insights can be gained by understanding the interplay between them. Specifically, Boland and Pondy suggest that these myths form a "figure-ground" or a "foreground-background" relationship to one another but that this relationship can change. In system development, the rational myth is exceptionally important because of the close association between computing and logical 
decision processes. Designing a system haphazardly or in an overtly political manner would violate most organizations' cultural norms of rationality. The rational myth thus assumes a "foreground" position, and the tangible trail of evidence (project schedules, meeting agendas, etc.) shows that the actors have behaved in accord with such cultural expectations. The "background" myth of political behavior is no less important, but it is culturally less acceptable. As with any background, however, it represents the broad context against which the more rational elements can be seen.

This relationship suggests that political interests are of basic importance to the actors in the organization. Political actions are not isolated episodes to be interpreted within the context of rational problem solving efforts. It is the other way around. The rational elements are tools used by participants to gain new ground or to protect ground already won. They also serve as "facades" to mask political motives and legitimize self interest.

What are the implications of our analysis for managing system development? Clearly, one insight is that naive actors in political situations are at a disadvantage. Knowledge of political processes includes awareness of the role which rational procedures play. Structured methodologies must be honored because they are part of the lore of system development, quite apart from their usefulness as rational tools. Being effective politically does not mean being clever to the point of arousing suspicion about one's motives. One must always be able to justify one's decisions in terms that are regarded as legitimate within the organization's culture.

\section{REFERENCES}

Burrell, G., and Morgan, G. "Socioligical Paradigms and Organizational Analysis: Elements of the Sociology of Corporate Life," Heinemann Publishing, London, England, 1979.

Cash, J.I, McFarlan, F.W. and McKenney, J.L. "Corporate Information Systems Management: Test and Cases," Richard D. Irwin, Inc., Homewood, Illinois, 1983.

Fuerst, W.L., and Cheney, P.H. "Factors Affecting the Perceived Utilization of Computer-based Decision Support Systems in the Oil Industry," Decision Sciences, Volume 1, 1982, pp. 554-569.

Ives, B., and Olson, M.H. "User Involvement and MIS
Success: A Review of Research," Management Science, in press.

Kling, R. "Social Analyses of Computing. Theoretical Perspectives in Recent Empirical Research," Computing Surveys, Volume 12, 1980, pp. 61-110.

Lucas, H.C., Jr. "The Analysis, Design and Implementation of Information Systems," McGraw-Hill, New York, New York, 1976.

Minzberg, H. "Power In and Around Organization," Prentice-Hall, Englewood Cliffs, New Jersey, 1983.

Robey, D., and Farrow, D.L. "User Involvement in Information System Developement A Conflict Model and Empirical Test," Management Science, Volume 28, 1982, pp. 73-85. 